\title{
La oralidad y sus metáforas en las aulas de clase*
}

\author{
DIEGO ARIAS CORTÉS**
}

Recepción: 30 de octubre de 2020

Aprobación: 27 de diciembre de 2019

Forma de citar este artículo: Arias, D. (2020). La oralidad y sus metáforas en las aulas de clase. Cuadernos de Lingüistica Hispánica, (35),2017-226, 179-198.

10.19053/0121053X.n35.2020.10622

* Artículo de investigación. Este trabajo es fruto de las apuestas académicas del grupo de investigación: "El discurso oral en el Quindío: de la academia a la cotidianidad" (DOQAC). Grupo reconocido por la Licenciatura en Literatura y Lengua Castellana de la Universidad del Quindío.

** Magíster en Estudios Hispánicos, de la Universidad de Cádiz, España. Docente de Lingüística en la Universidad del Quindío, Colombia. Correo electrónico: dariasc@uniquindio.edu.co @ https://orcid.org/0000-0002-8748-4452 


\section{Resumen}

Este artículo busca aportar teórica y metodológicamente al ámbito de la enseñanza de la lengua oral en las aulas, específicamente en la educación media colombiana y en lo que se ha denominado metáforas de la vida cotidiana. Para ello, se parte de algunas consideraciones teóricas sobre la oralidad como performance y como texto oral; además, se define la metáfora desde el campo de la lingüística cognitiva. Posteriormente, se exponen unos procedimientos orientados a la enseñanza de las metáforas de la vida cotidiana que, para este caso, tienen una fuerte filiación en la oralidad. Se culmina con unas conclusiones acerca de la enseñanza de la oralidad y de sus metáforas. Se destaca, entonces, que la oralidad, entendida como performance 0 texto oral, es otra dimensión del conocimiento que no debe ser evaluada desde los parámetros de la cultura letrada.

Palabras clave: oralidad; performance; texto oral; metáforas de la vida cotidiana; memoria colectiva; enseñanza de la lengua oral.

\section{Orality and its Metaphors in the Classroom}

\section{Abstract}

This article seeks to contribute theoretically and methodologically to the oral language teaching in the classrooms, specifically in the Colombian high school in what has been called everyday life metaphors. For this purpose, we start with some theoretical considerations about orality as performance and as an oral text; besides, metaphor is defined from the cognitive linguistic. Later, some procedures on everyday life metaphors are exposed, which, for this case, have a strong identity in orality. The paper finishes with the conclusions on the teaching of orality and its metaphors. We highlight that orality -understood as performance or oral text- is another dimension of the knowledge that should not be evaluated from the literate culture.

Keywords: orality; performance; oral text; everyday life metaphors; collective memory; oral language teaching. 


\section{LOralité et ses métaphores dans la salle de classe}

\section{Résumé}

La proposition énoncée dans ce document cherche à contribuer, de points de vue théorique et méthodologique, à l'approfondissement du domaine de l’enseignement des langues orales dans les salles de classe et, tout particulièrement, de leenseignement secondaire colombien, en termes de ce qui est convenu d'appeler des métaphores de la vie quotidienne (Lakoff et Johnson , 1986). Pour ce faire, quelques considérations théoriques autour de l'oralité, comme performance (Vich et Zavala, 2004) et comme texte oral (Moreno, 2011), ont constitué notre point de départ. En outre, la métaphore est définie dans le cadre de la linguistique cognitive (Cuenca et Hilferty, 2007). Nous passons, par la suite, à faire l'exposé de procédures qui prétendent enseigner les métaphores de la vie quotidienne qui, dans ce cas, sont en rapport avec l'oralité. Il se termine par quelques conclusions concernant l'enseignement de l'oralité et ses métaphores. Il ressort donc que l'oralité, comprise comme performance ou texte oral, est une autre dimension de la connaissance qui ne doit pas être évaluée à partir des paramètres de la culture lettrée.

Mots clés: Oralité; performance; texte oral; métaphores de la vie quotidienne; mémoire collective; enseignement de la langue orale.

\section{Oralidade e suas metáforas em salas de aula}

\section{Resumo}

A proposta desenvolvida neste documento procura contribuir teórica e metodologicamente para o campo do ensino da língua oral nas salas de aula, especificamente no ensino médio colombiano e em termos do que tem sido chamado de metáforas da vida cotidiana (Lakoff e Johnson 1986). Para isso, parte de algumas considerações teóricas em torno da oralidade como performance (Vich e Zavala, 2004) e como texto oral (Moreno, 2011); além disso, a metáfora é definida no campo da Linguística Cognitiva (Cuenca e Hilferty, 2007). Posteriormente, abre caminho para a exposição de procedimentos que visam ensinar as metáforas da vida cotidiana que, neste caso, têm uma forte conexão na oralidade. Termina com algumas conclusões sobre 0 ensino da oralidade e suas metáforas. Destaca-se, então, que a oralidade, entendida como performance ou texto oral, é outra dimensão do conhecimento que não deve ser avaliada a partir dos parâmetros da cultura letrada.

Palavras-chave: oralidade; performance; texto oral; metáforas da vida cotidiana; memória coletiva; ensino da linguagem oral. 


\section{Introducción}

La oralidad está presente en las aulas. Dejó de ser un apéndice en la enseñanza de las instituciones educativas colombianas. Prueba de ello es su presencia en los Derechos Básicos de Aprendizaje, volumen 2, del Ministerio de Educación Nacional (MEN, 2016). Este documento le otorga un lugar a su enseñanza, que se equipara con el creciente interés por los estudios del discurso multimodal (Pardo \& Forero, 2016) y se articula con la ya conocida propuesta educativa de las prácticas lectoescritoras, consolidada con la enseñanza de los géneros textuales.

En la actualidad no se discute sobre si se debe enseñar o no la oralidad, más bien, se debaten las propuestas que pretenden acercarla a las aulas de clase, tanto en escuelas y colegios, como en universidades. Muestra de ello son las diferentes apuestas que emergen en eventos académicos cada año en Colombia. Así, entre el 2016 y 2017, Red Lenguaje $^{1}$ realizó foros y talleres en diferentes ciudades que han contribuido a consolidar un campo de acción: la enseñanza de la oralidad en las aulas de clase. Algunos trabajos, presentados en forma de ponencia en estos eventos, resultan representativos; por ejemplo: "La interacción verbal en el aula: escenario para la inclusión de la población diversa" de González (2016); "Desafíos para maestros interesados en la enseñanza de prácticas de oralidad" de Gutiérrez, Cárdenas, Torres, Parra y Pinilla (2017); "Prácticas orales en la escuela: perspectivas y desarrollos" de Uribe y Montoya (2017); por último, "Aspectos generales de un modelo de oralidad en la Universidad ICESI" de Ortega, Montaño y Zúñiga (2017).

En este ámbito es que se sitúa la presente propuesta. De ahí el interés por aportar un marco teórico que guíe futuras prácticas relacionadas con la enseñanza de la lengua oral en el aula. De esto se desprende, también, una contribución metodológica que intenta ilustrar cómo la oralidad, con sus metáforas cotidianas, se puede acercar a la educación media colombiana.

Lo anterior se justifica por dos razones: 1) porque explorar la oralidad, trabajar con ella, conduce inevitablemente a actualizar la memoria colectiva (Vich \& Zavala, 2004) de una comunidad determinada; esto es, aquella conformada por los jóvenes estudiantes de los grados décimo y undécimo de instituciones educativas quindianas, con quienes se aplica, en parte, esta propuesta. 2) Este trabajo responde parcialmente a las

1 Red Colombiana para la Transformación de la Formación Docente en Lenguaje. Los eventos, publicaciones y memorias de esta red se pueden consultar en el siguiente enlace: https://www.redlenguaje.com/index.php 
preocupaciones que Moreno (2011) ha manifestado en cuanto al lugar de la oralidad en la educación colombiana. En su libro Narrativas de la oralidad cultural en el contexto colombiano, él advierte que la oralidad ha permanecido al margen de los microcurrículos de nuestras instituciones educativas, desconociendo, en consecuencia, lo que señala la Constitución Política de Colombia de 1991 (Título 1, artículo 7): "El estado reconoce y protege la diversidad étnica y cultural de la Nación colombiana"; artículo 8: "Es obligación del Estado y de las personas proteger las riquezas culturales y naturales de la nación" (citado por Moreno, 2011, p. 65). En otras palabras, dada la riqueza y diversidad cultural de nuestra nación, este investigador reconoce que el saber cultural (el conocimiento en general) no se puede limitar solo a un hecho letrado; por el contrario, debe indagarse en otras dimensiones, una de ellas es la del discurso oral.

\section{Elementos teóricos}

\section{La oralidad comoperformance: otra dimensión del conocimiento humano}

La oralidad no es solo palabra hablada, lo que escuchamos decir a alguien más; no es simplemente la imagen mental que me produce lo que alguien dice cuando está contando, por ejemplo, una anécdota. La oralidad no es un calco de la escritura, o sea, no es "perfecta" en términos gramaticales, ni reproduce el código escrito; no es un sistema de transcripción de la escritura. Valorada desde la óptica del escritor, del estudioso del texto escrito, la oralidad parece estar llena de imperfecciones: repeticiones, vacilaciones, silencios, frases a medio hacer, digresiones, sinsentidos, faltas de concordancia, abundancia de coloquialismos, ritmos frenéticos que no nos permiten entender lo que se dice, articulaciones extrañas de la palabra, etc.

No obstante, sus "imperfecciones" no son tales, y ya está claro que la oralidad es más que palabra hablada, va más allá de la imagen mental que produce un discurso oral y es un código diferente de la escritura. Lo anterior se sustenta en los cuatro trabajos que se revisan brevemente a continuación.

En primer lugar, Vich y Zavala (2004) definen la oralidad como una performance, un evento y una experiencia, que se dan en circunstancias particulares. En el primer capítulo de su libro: Oralidad y poder. Herramientas metodológicas, la caracterizan, la desmarcan de las prácticas letradas (Barton \& Hamilton, 1998) que la han reducido a palabra hablada. Entonces, según estos autores peruanos, la performance involucra otras dimensiones: el gesto, el movimiento, la audiencia, etc. Agregan que cada puesta en escena oral tiene una autoría colectiva; es decir, pertenece a quienes la emplean, pues en muchas ocasiones su sentido y desarrollo dependen de la aprobación o no de un 
público, no solo de quien propone el discurso. Otro de los rasgos que destacan es que a través de ella es como se actualiza el pasado de una comunidad. Esto, porque asumen que el pasado no existe como algo que queda atrás, sino, más bien, es una posibilidad latente que toma forma, se actualiza, se hace realidad cuando se verbaliza. En otras palabras, "[...] muchos de los discursos orales son formas de memoria colectiva a través de las cuales los sujetos encuentran fundamentos para constituir su identidad y repensar su presente" (p. 18).

En segunda instancia, Cassany (1999), al comparar el código escrito con el oral, deja entrever, sin proponérselo, que esas posibles imperfecciones de la oralidad no son más que rasgos de esta, que la diferencian del código escrito. Señala que el código oral tiende "a marcar la procedencia dialectal del emisor" (p. 37) y el escrito es más neutral en este sentido. En el primer código hay una "Alta frecuencia de anacolutos y frases inacabadas" (p. 39), en el segundo, su ausencia es casi obligada. También sostiene que la oralidad requiere de muchos recursos paralingüísticos y de códigos no verbales: cambios de ritmo y velocidad, variación de tonos; movimientos oculares y corporales, gestos, etc.

En una línea semejante a Cassany (1999) y Vich y Zavala (2004), pero con un interés diferente, Pacheco (2016) indaga acerca de las diferentes concepciones sobre la oralidad en contraste con la cultura escrita. Recurre entonces a la revisión de numerosos estudios al respecto. El inicio de estas investigaciones lo data en Parry (1928), específicamente en su trabajo sobre el origen oral de las obras de Homero. Apela también a Lord (1960), McLuhan (1962), Havelock (1963), Ong (1982), entre otros, con el fin de obtener un panorama más amplio de la situación del hecho oral con respecto al escrito. Esta revisión lo lleva a concluir:

[...] la oralidad no puede, entonces, concebirse solo como el predominio de una modalidad comunicacional, tampoco, en términos negativos, como privación o uso restringido de la escritura ni, finalmente, como una suerte de subdesarrollo técnico 0 atraso cultural, sino como una auténtica economía cultural, relativamente autónoma, que implica-en relación directa con ese predominio o exclusividad de la palabra oral- el desarrollo de peculiares procesos de conocimiento, concepciones del mundo, sistemas de valores, formas de relación con la comunidad, con la naturaleza, con lo sagrado, usos particulares del lenguaje, nociones de tiempo y espacio y, por supuesto, ciertos productos culturales con características específicas que difieren en mayor o menor grado, pero de manera siempre significativa, de sus equivalentes en culturas dominadas por la escritura, la imprenta o los medios electrónicos. (p. 54) 
Por último, Moreno (2011), en Colombia, se ha empeñado en defender la oralidad, en ubicarla en relación con las prácticas letradas y en entender cómo ambos universos conviven y se diferencian a la vez. Así, con respecto a una práctica letrada como la literatura, señala:

Una de las tendencias teórico-epistemológicas que más han influido en el no conocimiento-reconocimiento de la oralidad como realidad concreta de la cultura es la que pretende que la oralidad es un fenómeno que puede ser integrado al dominio de lo literario. Se presume que esta es un objeto literario, lo que trae como consecuencia, principalmente, que se la desnaturaliza al mismo tiempo que se la considera en un rango inferior dentro de los géneros literarios (Moreno, 2011, p. 34).

De ahí la necesidad, afirma él, de diferenciar los textos orales de los literarios y así evitar "las amalgamas mistificadoras y jerarquizadoras" (Moreno, 2011, p. 34). Esto lo lleva a plantear cinco rasgos de lo que denomina textos orales ${ }^{2}$ a) no son textos de autor, b) su existencia como lengua escrita es un accidente, c) no son reductibles a un género, d) su inteligibilidad solo es posible dentro del marco de la inteligibilidad de la tradición que las comprende y e) su materialidad textual es modificable.

Como puede observase, los trabajos descritos se acercan a la oralidad desde diferentes puntos de vista, pero coinciden en que el hecho oral tiene unas coordenadas bien delimitadas, alberga unas características propias y, sin lugar a dudas, es una de las tantas posibilidades de elaboración y transmisión de conocimiento. Por ende, obviar su existencia, al no incluirla en los derroteros que guían el quehacer del docente en el área de leguaje, es también negar la posibilidad de reconocernos como una cultura que debe parte de su identidad y conocimiento al universo oral en el que habita.

\section{Las metáforas de la vida cotidiana}

Antes de entrar en definiciones, se presentan algunas metáforas de la vida cotidiana (MVC) en la Tabla 1.

2 Los rasgos se encuentran a lo largo de la página 35 de la obra referida. 
Tabla 1. Metáforas orientacionales ${ }^{3}$

\begin{tabular}{|l|}
\hline \multicolumn{1}{|c|}{ Arriba } \\
\hline 1. Esa noticia me levantó el ánimo. \\
\hline 2. Bájate de esa nube. \\
\hline 3. Me siento volar contigo. \\
\hline 4. Toqué el cielo con las manos. \\
\hline 5. Este muchacho va cogiendo vuelo. \\
\hline
\end{tabular}

Cuando se piensa en la expresión de 1, da la impresión de que el "ánimo" es una cosa concreta que puede "levantarse", como un objeto que se ha caído. No obstante, se sabe que el ánimo es algo abstracto, que refiere a un estado emocional. En 2, se señala que el cielo y sus alturas son las coordenadas apropiadas para el bienestar emocional, pues la expresión la usamos para referirnos a alguien que experimenta un sentimiento agradable o se hace ilusiones con respecto a algo positivo. En 3, de nuevo, el cielo, las alturas, se utilizan para describir cómo es esa experiencia maravillosa (cuando lo es) de estar con alguien. En 4 y 5 sucede algo semejante a los enunciados anteriores: arriba, en lo alto, se ubican las referencias para expresar que alguien se sintió muy bien y que está progresando.

De 1 a 5 tenemos MVC, y tan cotidianas son, que generalmente no se advierte que apelamos a ellas en las interacciones comunicativas diarias. En términos generales, consisten en comparar dos universos de sentido, o de acercarlos, si se quiere. Después se funden en uno solo. Entonces, como se observa en los cinco enunciados, se compara el cielo (arriba) con sensaciones de bienestar, de progreso, etc. Por lo tanto, "el sentirse bien" y "el cielo" se acercan y se codifican en el lenguaje para comunicar, para fundirse ya no en una comparación, sino en un nuevo producto lingüístico: no se trata de "el bienestar" se parece "al cielo", sino: "en el cielo (arriba) habita el bienestar".

Con base en ejemplos de este tipo, tomados de discursos informales, Lakoff y Johnson (1986) definieron la metáfora en los siguientes términos: "La esencia de la metáfora es entender y experimentar un tipo de cosa en términos de otra" (p. 41). De ahí que experimentemos y entendamos el amor, la dicha, el buen ánimo y el progreso como si estuvieran ubicados arriba; así se codifican dichas experiencias en el lenguaje.

3 Los ejemplos de esta tabla son producto de algunas pesquisas por parte del grupo de investigación El discurso oral en el Quindío: de la academia a la cotidianidad, entre los años 2016 y 2017. Son ejemplos tomados de la realidad cotidiana. 
Lo contrario también sucede: la tristeza, la enfermedad y la falta de bienestar, pueden expresarse metafóricamente en el lenguaje con referencia a algo que está abajo: "estoy hecho polvo", "tengo las defensas bajas", "estoy por el piso con el jefe", etc.

Cuenca y Hilferty (2007) afirman que la metáfora desde esta perspectiva:

No se contempla como una mera figura retórica, ni tampoco como una anomalía lingǘstica; al contrario, se entiende como un proceso cognitivo que impregna nuestro lenguaje y pensamiento habitual. [...] la base de la metáfora radica en nuestro sistema conceptual: constituye un mecanismo para comprender y expresar situaciones complejas sirviéndose de conceptos más básicos y conocidos. (p. 98)

La cita anterior brinda un valor agregado a la metáfora, pues la deslinda del uso exclusivo de la literatura y de los discursos formales, situándola también en el lenguaje cotidiano donde se la entiende como un dispositivo o proceso cognitivo más.

En ambas obras referidas se presentan los diferentes tipos de metáfora que a menudo empleamos en la cotidianidad. Interesan acá las que se denominan como metáforas conceptuales, es decir: "[...] esquemas abstractos [...] que sirven para agrupar expresiones metafóricas. Una expresión metafórica, en cambio, es un caso individual de una metáfora conceptual" (Lakoff \& Johnson, 1986, p. 100). En consecuencia, una expresión como "El bienestar habita arriba" es equivalente a una metáfora conceptual, ya que se establece como un esquema abstracto en el que puede organizarse la experiencia codificada en expresiones metafóricas como las enlistadas en la Tabla 1. Un ejemplo más: "Los humanos son máquinas" es una metáfora conceptual que engloba la experiencia de expresiones metafóricas como: a) "se te cayó un tornillo", b) "baje las revoluciones", c) "estás muy oxidado", d) "hay que cambiar el chip a los estudiantes" y e) "apague el radio" (para cuando alguien habla en exceso).

En todos estos ejemplos hay una comparación entre una especie de máquina 0 artefacto y un ser humano. Aunque no se trata solo de una comparación, pues como se ve, ese ser humano asimila alguna propiedad de aquello con lo que se compara para convertirse en una nueva entidad. De ahí que la expresión "Los humanos son máquinas" adquiera el valor de metáfora conceptual, puesto que reúne todas las características manifiestas en los ejemplos citados (a y e) y se revela como una manera de experimentar y entender el mundo, de organizar la experiencia con respecto a este. En últimas, se corresponde con lo que se entiende por procesos cognitivos: formas que tiene nuestra 
mente de organizar, conceptualizar y recuperar la información que percibimos de nuestro entorno (Smith \& Kosslyn, 2008).

Para cerrar este apartado, hay que señalar que con respecto a las MVC se han hecho varios estudios. Ejemplo de ello es el trabajo de Segura (2012), en Costa Rica, en relación con las MVC provenientes del argot futbolero de ese país. Otra posibilidad, pero en Colombia, es el artículo de Ramírez (2007), en el que se propone demostrar que en las expresiones metafóricas de las narraciones de mujeres subyace la metáfora "la vida es un viaje", mientras que en los hombres permanece la idea de "la vida como un escenario".

\section{La enseñanza de la oralidad en las aulas}

El interés en nuestro país por la enseñanza de la lengua oral en las aulas de clase se ha incrementado. Como se señaló, Red Lenguaje ha dado la oportunidad para que quienes trabajan en este ámbito puedan compartir sus inquietudes y avances respectivos. Pero también se pueden encontrar iniciativas en otros espacios que, directa 0 indirectamente, se acercan a la oralidad. A continuación, un par de ejemplos.

Primero, el caso de Motta (2017, p. 150), cuyo interés es: “[...] dar cuenta de la actitud de escucha de estudiantes y docentes como fundamento de la comunicación y la democracia en el aula de clases”. Esto, porque él considera que:

[...] la escucha es la habilidad fundante de los actos del lenguaje, puesto que antes de hablar, leer o escribir, el ser humano ha activado la facultad de lenguaje y estructurado su sistema de comunicación que es básicamente oral, a partir de los procesos de audición y escucha. (Motta, 2017, p. 155)

Además, porque "[...] la escucha se está percibiendo como una disonancia y un déficit en la construcción ciudadana” (Bickford, citado por Motta, 2017, p. 152).

Otra iniciativa que aborda algunos aspectos de la oralidad es la de Corredor y Romero (2010), específicamente lo que denominan conversación constructiva y que definen así:

[...] una interacción discursiva adecuada y pertinente, producto de un contexto y enmarcada en un entorno sociocultural, que se da en el plano de lograr objetivos comunes de los interlocutores; se trata de una acción dialogal en busca de avenencia o de un intercambio de saberes, actitudes, voliciones y sentimientos entre dos o más interlocutores, quienes se expresan con confianza, proponen al otro u otros su visión de mundo, ofrecen datos, dejan ver imaginarios para, a través del intercambio lingüístico, enriquecerlos y, cuando sea necesario, enriquecer los 
del interlocutor; todo, en procura de lograr acuerdos, insistir en desavenencias, terquedades, caprichos o, sería el fin último y encomiable, facilitar la convivencia. (pp. 99-100)

También establecen unas pautas para esta, por ejemplo: el respeto, la disposición a escuchar y ser escuchado, el silencio, la consideración del lenguaje no verbal, el hecho de que no siempre se tiene la razón o se está equivocado, el poder corregir y autocorregirse, etc. Tras su definición y caracterización, proponen llevarla a las aulas de clase y para ello plantean algunas actividades pedagógicas (Corredor \& Romero, 2010, pp. 103-105).

\section{Procedimientos}

\section{Consideraciones generales}

Antes de presentar las actividades que ilustran una posible vía de enseñanza de la oralidad, de sus metáforas cotidianas, es importante establecer algunas directrices generales que son consecuencia lógica de la concepción de la oralidad comoperformance o como texto oral.

1. El docente que pretenda aplicar las actividades (del parágrafo 2.2. que viene a continuación) en su aula de clase, debe explorar las metáforas orales por su propia cuenta; es decir, antes de enseñarlas es importante que se familiarice con ellas no solo a través de la teoría sino de un pequeño corpus lingüístico que puede recoger gracias a notas diarias de campo. Las descubrirá entonces en los lugares y momentos menos pensados y advertirá la sutileza de sus texturas. Ejemplo de ello: "Me voy a chorriar por esa cuadra pa'coger el bus". Esto lo dijo una mujer justo cuando pretendía bajar por una calle para abordar el transporte intermunicipal.

2. Se debe tener en cuenta que no se concibe la evaluación de las actividades del parágrafo 2.2, pues estas se han pensado más para experimentar (vivenciar, recordar, reconocer, etc.) la metáfora.

3. Dado que el objetivo no es evaluar estas metáforas de la oralidad, sino experimentarlas, se espera que al final de cada sesión se reflexione 0 converse sobre lo sucedido en el aula en relación con esta temática, porque el intercambio dialógico caracteriza la oralidad y determina la autoría misma del discurso. 
4. El punto 3 también pretende que se apele a la memoria colectiva del grupo para que se identifiquen y reconozcan en las diferentes metáforas que cada estudiante pueda recordar 0 elaborar.

5. Las actividades que vienen a continuación podrían funcionar también como una fase inicial de una transposición didáctica (Gómez, 2005) ${ }^{4}$ más amplia, cuyo fin principal sea enseñar la metáfora literaria. De esta manera, una posibilidad de la oralidad sería integrarse al currículum como un paso previo en la enseñanza de algún aspecto de la escritura.

\section{Las actividades}

Como se señaló en el punto 5 del parágrafo anterior, las actividades que vienen a continuación se pueden integrar a un ejercicio didáctico amplio que implique varias sesiones. Este podría basarse, por ejemplo, en los DBA (Ministerio de Educación Nacional de Colombia [MEN], 2016) para grado décimo, enunciado 5; para grado 11 se puede partir del enunciado número 2.

Así, las actividades para realizar son las siguientes.

\section{Actividad $1^{5}$}

Título de la actividad: Sensibilización

Objetivo: practicar la capacidad descriptiva de los estudiantes

Tiempo de la actividad: 90 minutos

Materiales: octavos de cartulina, lápices y colores

Entorno: independientemente del lugar donde se lleve a cabo la actividad, se espera que los chicos puedan estar relativamente dispersos, pero visibles para el docente encargado. Esto con el fin de romper con la formalidad que suele imponer la organización del espacio en las aulas y, por supuesto, de contribuir a que la experiencia sea más relajada.

4 Gómez (2005, p. 87), siguiendo a Chevallard (1985), afirma: "El concepto de transposición didáctica remite entonces al paso del saber sabio al saber enseñado y luego a la obligatoria distancia que los separa. Hay de esta forma transposición didáctica (en el sentido restringido) cuando los elementos del saber pasan al saber enseñado".

5 Las tres actividades que se presentan en este apartado se diseñaron en el 2017 en el grupo de estudio: El discurso oral en el Quindío: de la academia a la cotidianidad (DOQAC). Dos de ellas se aplicaron (la 1 y la 3) en un taller en la Institución Educativa Ciudadela de Occidente, en el Barrio Universal, de la ciudad de Armenia. La número 2 aún no se ha llevado a la práctica. 


\section{Descripción:}

a. Los estudiantes se forman en parejas.

b. A uno de ellos se le entregan lápiz, colores y el octavo de cartulina. En este realiza un retrato del compañero, y en la parte inferior del dibujo escribe las cualidades más destacadas de esa persona.

c. Se entregan los retratos al docente.

d. El docente exhibe algunos retratos para todos los integrantes del curso, sin que se visualicen las cualidades escritas. También puede leer en voz alta las cualidades de algunas de las personas dibujadas (sin mostrar el retrato). El fin es que los compañeros adivinen de quién se trata, sea porque ven el retrato 0 porque reconocen las cualidades como inherentes a alguien.

e. Las tres personas que más adivinen la identidad de sus compañeros (los turnos en este ejercicio se dan cuando se levanta la mano) recibirán algún tipo de incentivo.

f. Se termina con una pequeña discusión de las impresiones que surgen a partir de este ejercicio.

Justificación: este ejercicio busca aguzar, principalmente, la capacidad descriptiva de los chicos. Esto, porque las MVC implican el acercamiento de dos universos (realidades, objetos, circunstancias, dominios, etc.) de los cuales reconocemos y usamos varias de sus características.

\section{Actividad 2}

Título de la actividad: Las MVC en el aula

Objetivo: comprender el sentido y utilidad de las MVC empleadas en el aula de clase

Tiempo de la actividad: 45 minutos

Materiales: pelucas, papeles arrugados para lanzar en clase, letreritos de papel sujetos a palillos, una grabación de: una voz en off, de risas, de un timbre de descanso

Contexto: un auditorio o adecuación del salón a manera de pequeño teatro 
Descripción: esta actividad requiere de la preparación de una obra de teatro. $\mathrm{Su}$ duración es de cinco minutos. En los diálogos que contiene se aprecian algunas MVC. Se espera que tras la presentación de la obra de teatro, se pueda discutir sobre el significado de esas metáforas. Para la realización de la obra se requieren siete estudiantes y el docente encargado. En dos sesiones prácticas de 40 minutos se puede aprender la obra y luego presentarla a los compañeros.

\section{Obra de teatro}

Título: La cogieron de tema

Personajes: Colitas (estudiante), Cachetes (estudiante), Odiosa ("Odi", estudiante), Intensa (estudiante), Bad Boy (estudiante), Profe Lourdes, Rector (Don Justino), Voz en off, Narrador.

\section{Única escena}

[En un aula de clase todos los personajes están sentados, recostados en sus pupitres como si durmieran en ellos. Los pupitres están en diagonal con respecto al auditorio. De repente, la profe se levanta de su puesto, golpea el tablero con un marcador y todos se activan e inicia la obra]

Profe Lourdes: vamos a hablar del significado de las imágenes. Estas son representaciones de la realidad y tienen funciones simbólicas. 0 sea, es como si una imagen fuera una especie de poder porque sirve para mostrar algo que no está presente o está muy lejos sin necesidad de ir hasta donde eso se encuentra, ¿me hago entender, amores míos?

[Después de preguntar esto, la profe empieza a caminar de un lado a otro mientras escucha las intervenciones de los estudiantes].

Bad boy: uff, qué terapia esta cucha con esas "raras" [Le susurra a Odi y esta mueve la cabeza en señal de asentimiento].

Profe Lourdes: ¿qué dijo, jovencito? iA ver, no lo escuché!

Bad boy: pro, naaada, reláaaaajese.

Profe Lourdes: mucho cuidado, halándole al respetico, señor.

Cachetes: pro, cuando se habla de imágenes podemos pensar en una foto, ¿cierto? 
Profe Lourdes: sí, claro [Colitas está levantando la mano] ... iDime! [Se dirige a Colitas].

Colitas: también podemos referirnos al aspecto físico de una persona y al parecido con otra, como mi papá y mi abuelo... [Lo dice sin mirar a la profe y juntando las manos, ansiosa].

Intensa: pero también a representaciones mentales, ideas o conceptos que se construyen sobre algo [Dice esto interrumpiendo a Colitas, y se le nota el afán por participar].

Odi: icállese, comelibros! [Mientras dice esto, le lanza un papel a Intensa que le da justo en la cabeza. Los demás estudiantes también arman desorden, lanzan cosas, gritan y patalean un poco].

Voz en off: la profesora Lourdes es solicitada en la rectoría. Repito: la profesora Lourdes es solicitada en rectoría [Esta llamada proviene de una grabación].

Profe Lourdes: [ante semejante desorden, se ve que la profe regaña a los estudiantes e intenta calmarlos. Sin embargo, no habla sino que hace la mímica de lo que está hablando, de igual forma se ve que los estudiantes hacen desorden pero en mímica. Luego se calman. Después ella sigue en el tablero con sus explicaciones, improvisando y haciendo caso omiso a la voz en off que de nuevo la convoca a rectoría].

Voz en off: la profesora Lourdes es solicitada en la rectoría. Repito: la profesora de español, Lourdes, es solicitada en la rectoría.

Narrador: la profe no atiende el llamado y sigue en el tablero. De repente, cuando todo está en calma, mira a los estudiantes y descubre los pensamientos de Odi.

Odi: "iah! Que clase tan harta, estas pendejadas que dice esta vieja no me las aguanto, ivieja estúpida!”. [Como son pensamientos, estos se ven reflejados en unos letreritos de papel sujetos a unos palillos de madera].

Profe Lourdes: ¿qué? Cómo así señorita, no me gusta lo que está pensando [Lo dice histérica, y se despacha con un motón de regaños improvisados].

Narrador: de pronto tocan a la puerta. Es el rector, don Justino (él lleva un letrerito visible a todos, que dice: "don Justino, rector").

Rector: profesora Lourdes, serían tan amable de acompañarme a mi oficina. 


\section{Profe Lourdes: sí, señor rector.}

Narrador: mientras tanto, los estudiantes hacen lo que más les gusta: el caos en el aula.

Odi: [toma la silla de la profe y se sitúa justo en la entrada del salón. Se alborota el pelo para parecerse a la profe. Se para encima de la silla y empieza a hablar de forma provocativa: Pues si se trata de representaciones: Cachetes parece una marrana soplada (todos los estudiantes se carcajean), Colitas se voló de la película El Aro e Intensa parece un gancho de ropa...]

Bad boy: ija! (mirándose las uñas) ¿Y usted a qué se parece? (pausa)

Estudiantes: iuuuuyyyy!

Odi: no sea sapo, no se meta.

Bad boy: ya, aletosa, cálmese. Yo creo que a la profe no le faltan sino alas para salir volando con los chulos [Suenan las risas pregrabadas].

Narrador: justo en ese momento la profe ingresa al salón y escucha a Bad Boy diciendo semejante cosa.

Profe Lourdes: [pone los brazos en jarra, furiosa] Joven, mida sus palabras si no quiere que lo reporte por indisciplina. Odi, perdón, perdón, Alejandra, a su lugar [le grita].

Narrador: todos vuelven a su lugar y se calman. Un silencio se apodera del salón, y los pensamientos de la profe afloran, tristes y oscuros [de nuevo aparecen unos letreritos que muestran los pensamientos de la profe], pues el rector la ha dado de baja como docente de esta institución.

[Para finalizar, suena un timbre (pregrabado) y todos salen alegres, excepto la profe Lourdes que camina cabizbaja].

Fin de la obra

Justificación: se busca que los estudiantes comprendan el significado, así como la función discursiva de algunas MVC empleadas en un contexto simulado, el del aula de clase. Tras la presentación, se espera que entre todos den cuenta del sentido y utilidad de las metáforas que allí aparecen. Para ello, el docente encargado las copia en el tablero y se discuten, estas son: "halándole al respetico", "conceptos que se construyen sobre algo", 
"Colitas se voló de la película El Aro", "Ya, aletosa, cálmese", "Joven, mida sus palabras", "la ha dado de baja". Esto enfatiza de nuevo la importancia de la participación de todos en la elaboración del sentido y contribuye a flexibilizar más los roles de docente-estudiante; esta coparticipación es un atributo de las comunidades orales y está en consonancia con uno de los rasgos ya referido de los textos orales: "su inteligibilidad solo es posible dentro del marco de la inteligibilidad de la tradición que las comprende".

\section{Actividad 3}

Título de la actividad: Creando y recordando metáforas

Objetivo: producir MVC con base en algunas ideas previas

Tiempo de la actividad: 45 minutos

Materiales: impresiones a color

Contexto: el salón de clases

Descripción: a grupos de tres estudiantes se les entrega una hoja en la que aparecen dos dibujos. Debajo de cada uno hay una descripción con las características que lo componen, como se observa en la Figura 1.
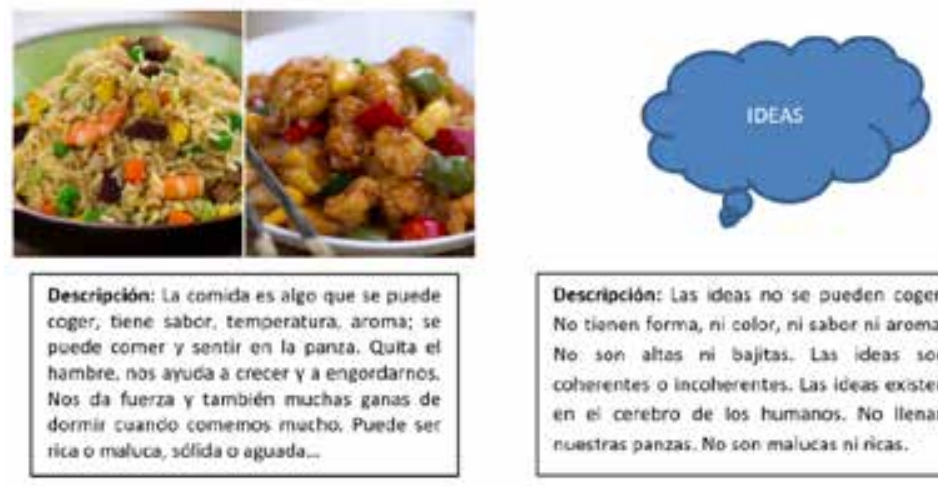

Descripcion: tas ideas no se pueden coger. No tionen forma, ni color, ni saber ni aroena No son ahas ni bajitas. Las ideas son coherentes o incoherentes. Las ičeas existen en el ceretro de los humanos. No lienan nuestras panzas. No son malucas ni ricas.

Metáforas: "Huelen mal tus ideas", "No me trago tus ideas".

Figura 1. Las ideas y la comida en las metáforas

Tras observar atentamente los dibujos y leer las características, se solicita a los estudiantes que elaboren, al menos, cinco metáforas semejantes a las que aparecen en la parte inferior de la Figura 1. Las pueden escribir en el reverso de la hoja. Luego se les pide 
que elaboren un párrafo corto de diez líneas en el que usen estas metáforas. Finalmente se socializa el ejercicio. Para esto se pregunta por el valor de las metáforas en la vida cotidiana, por sus usos, por su utilidad en las interacciones del día a día, sea en el aula de clase o fuera de esta.

Justificación: esta actividad tiene su razón de ser, porque gracias a la producción de MVC de los estudiantes se puede entrever qué tanto se comprenden los conceptos, pero sin llegar a postularse como una actividad evaluativa que implique hacer algo para ser evaluado; en otros términos, se convierte en un indicador de la comprensión de los alumnos. Adicionalmente, funciona como una actividad que transita entre el universo de la oralidad y el de la escritura. Esto permite entonces que se pueda articular con otras actividades posteriores enfocadas directamente en la enseñanza de la metáfora literaria.

\section{Conclusiones}

En primer lugar, de lo presentado hasta el momento, hay que enfatizar que la oralidad es objeto de enseñanza y aprendizaje en las aulas colombianas. Esto lo respaldan los DBA (MEN, 2016) y las distintas propuestas que se han referido en este documento. Y dentro de las múltiples posibilidades que ofrece la oralidad, sus metáforas pueden ser llevadas a las aulas de clase, con el fin de experimentarlas, explorarlas y reconocerse en ellas como cierto tipo de comunidad. Esto conlleva, también, el descubrimiento de una memoria colectiva. A esta se llega gracias al aporte de quienes hacen parte del salón de clase, de sus intervenciones y puntos de vista. En otras palabras, esa memoria depende de una autoría compartida en la que se incluye la voz del otro y en la que no se pretende una verdad absoluta. En resumidas cuentas, la enseñanza-aprendizaje de la oralidad debería ser incluyente.

En segunda instancia, la oralidad no se agota en la palabra hablada. Es, como se señaló, otra dimensión del conocimiento: una performance y un texto oral. Esto quiere decir, entre otras cosas, que no se la debe evaluar ni juzgar desde los parámetros de la cultura letrada (tampoco se la debería reducir a letras puestas sobre un papel), ya que sus dinámicas se comprenden desde la misma cultura oral, desde sus propias formas de pensamiento y con base en los valores propios que instaura la comunidad oral. Ya señaló Pacheco (2016), que la oralidad es "una auténtica economía cultural".

En tercer lugar, se desprende del estudio de las MVC que estas expresiones metafóricas reflejan cómo las personas conceptualizan y elaboran el mundo en el discurso. De ahí que las MVC pueden ser un buen instrumento para caracterizar y comprender, en parte, lo que significa ser integrante de una determinada cultura. En el 
caso particular de este trabajo, daría la posibilidad de responder (parcialmente) a: ¿Qué significa ser estudiante de la educación media colombiana? ¿Qué implica ser parte de esa comunidad oral?

Por último, las concepciones de la oralidad planteadas acá repercuten en la manera de enseñarla. Así, en todas las actividades propuestas se instó a no evaluar. En lugar de ello, se sugirió un diálogo con los estudiantes en todas las actividades con el fin de reconstruir el sentido, entre todos, de aquello que se propuso en cada clase. Adicionalmente, las actividades también reflejan una dinámica distinta en relación con los roles del docente y estudiante, puesto que en ellas se crea una relación más simétrica, más cercana a la manera en que diariamente habitamos nuestra oralidad.

\section{Referencias}

Barton, D., \& Hamilton, M. (1998). Local Literacies. Reading and Writing in One Community. London/New York: Routledge.

Cassany, D. (1999). Describir el escribir. Cómo se aprende a escribir. Barcelona: Paidós.

Corredor, J. \& Romero, C. (2010). Apuntes lingüísticos, discursivos y pedagógicos sobre la conversación constructiva. Cuadernos de Lingüística Hispánica, (15), 93-108.

Cuenca, M. \& Hilferty, J. (2007). Introducción a la lingüística cognitiva. Barcelona: Ariel.

Gómez, M. (2005). La transposición didáctica: historia de un concepto. Revista Latinoamericana de Estudios Educativos, 1(1), 83-115.

González, C. (2016). La interacción verbal en el aula: escenario para la inclusión de la población diversa. En Ponencia presentada en IX Coloquio de la Maestría en Pedagogía de la Lengua Materna, Pedagogías de la Literatura, Oralidady Escritura. Bogotá. Recuperado de: https://www.redlenguaje.com/index.php

Gutiérrez, Y., Cárdenas, M., Torres, A., Parra, C., Pinilla, M. (2017). Desafíos para maestros interesados en la enseñanza de prácticas de oralidad. En Ponencia presentada en XIV Taller Nacional para la Transformación de la Formación Docente en Lenguaje. Pereira. Recuperado de: https://www.redlenguaje.com/index.php

Lakoff, G. \& Johnson, M. (1986). Metáforas de la vida cotidiana. Barcelona: Cátedra.

Ministerio de Educación Nacional de Colombia -MEN- (2016). Derechos básicos de aprendizaje. Recuperado de http://aprende.colombiaaprende.edu.co/sites/default/files/naspublic/ DBA_Lenguaje.pdf 
Moreno, J. (2011). Narrativas de la oralidad cultural en el contexto colombiano. Cali, Colombia: Universidad del Valle.

Motta, J. H. (2017). La actitud de escucha, fundamento de la comunicación y la democracia en aula. Cuadernos de Lingüistica Hispánica, (30), 149-169.

Ortega, O., Montaño, M., Zúñiga, J. (2017). Aspectos generales de un modelo de oralidad en la Universidad ICESI. En Ponencia presentada en XIV Taller Nacional para la Transformación de la Formación Docente en Lenguaje. Pereira. Recuperado de: https:// www.redlenguaje.com/index.php

Pacheco, C. (2016). La comarca oral revistada. Bogotá: Universidad Nacional de Colombia.

Pardo, N. \& Forero, N. (2016). Introducción a los estudios del discurso multimodal. Bogotá: Universidad Nacional de Colombia.

Ramírez, H. (2007). ¿Sedentarismo o nomadismo? La metáfora en el ámbito de la concepción de la vida en el habla cotidiana. Forma y Función, (20), 147-152.

Segura, G. (2012). Del fútbol a la metáfora de la cotidianidad. Revista Káñina, 36, 223-230.

Smith, E. \& Kosslyn, S. (2008). Procesos cognitivos. Modelos y bases neurales. Madrid: Pearson Educación.

Uribe, R., Montoya, J. (2017). Prácticas orales en la escuela: perspectivas y desarrollos. En Ponencia presentada en XIV Taller Nacional para la Transformación de la Formación Docente en Lenguaje. Pereira. Recuperado de: https://www.redlenguaje.com/index.php

Vich, V. \& Zavala, V. (2004). Oralidad y poder. Herramientas metodológicas. Lima: Norma. 